\title{
TERMINOLOGÍA DE PARENTESCO HARAKMBUT
}

\section{Heinrich Helberg Chávez}

$\mathrm{El}$ autor explicita el sistema de parentesco de los Harakmbut (Harakmbet) de la comunidad nativa deShintuya (Alto Madre de Dios), mediante el análisis dela terminología usada para verbalizar las relaciones de parentesco. Se hacer ver la complejidad del sistema de parentesco de este grupo específico, no solamente por el conjunto de realidades involucradas en tales relaciones (identidad, afiliación genética, afiliación "afinal", etc.); sino también porque las relaciones de parentesco se realizan en el mundo "real" y en el mundo "ficticio".

The author descrip the Harakmbut (Harakmbet) kinship system of the town of Shintuya (High Madre de Dios), by means of an analysis of the terms used to express kinship relations. It is complex not only because of the elements involved in these relationships (identity, consanguineal affiliation, affinal a ffiliation, etc.), but because the kinship relations are carried out in the "real world" and the "fictitious" world. 


\section{INTRODUCCIÓN}

Harakmbut significa 'la humanidad', el universo indígena amazónico, a diferencia de oa-kaipi 'los serranos', el hombre andino, o también ami?ko 'el hombre blanco'. Harakmbut es también el término que usan para designarse a sí mismos, a diferencia de los Matsigenka, Ese Eja, etc. que los rodean. Es también el nombre de su idioma: Harakmbut hate, "el habla Harakmbut'. La palabra Harakmbut contiene dos raices: el verbo arak'matar' y mbut' verdad. Por lo que Harakmbut posiblemente hace alusión a su etos guerrero: un pueblo que pudo resistir los embates de la Conquista, las guerras provocadas por los caucheros en búsqueda de esclavos y otras penetraciones "científicas" o misioneras, hasta los años cuarenta de este siglo, cuando ya muy diezmados por epidemias y guerras internas se realizaron los primeros contactos positivos con misioneros. El territorio tradicional Harakmbut abarcaba la margen derecha del río E?ori o ?ori-oe (el actual Madre de Dios) desde sus fuentes hasta el río Arãsã (Inambari), formando un extenso trapecio con su otra frontera natural: los Andes.

Es usual distinguir grupos culturales/dialectales entre los Harakmbut: Amarakaeri, Tõiōeri, Oatipaeri, Sapiteri, Kisambaeri, Arãsãeri. Con estos nombres suelen aparecer en la literatura. Las divergencias culturales son reales y significativas, pero pienso, que a pesar de todo se mantiene la unidad de lengua y cultura. El origen de los nombres para los subgrupos son apodos que les daban otros grupos o simplemente la denominación de los habitantes de una localidad: Tõiōeri significa 'gente que vive río abajo', Arãsãeri, los del río Arãsã, etc. Entre ellos sólo usan Harakmbut para definirse así mismos, pero los términos Amarakaeri, Oatipaeri, etc., los usan frente a otros y ya se han establecido, por lo que seguiremos usando de ellos. La investigación para el presente estudio ha sido realizada en la comunidad nativa de Shintuya (sobre el Alto Madre de Dios) en dos períodos de trabajo: 1976 y 1984/85. El estudio refleja, por lo tanto, el uso de la terminología de parentesco en esta comunidad, donde convive un pequeño grupo de Oatipaeri conjuntamente con uno más extenso de Amarakaeri, de los ríos Isirioe y Oandakoe principalmente. Uno de mis informantes había vivido muchos años en la comunidad de Puerto Luz (río Kãrẽnẽ o Colorado), por lo que me fue posible chequear alguna divergencia de usos. La tesis doctoral de Andrew Gray (Gray: 1983) nos demuestra que existe una importante variación en cuanto al uso de la terminología de parentesco entre diversas comunidades. Su excelente trabajo fue realizado en San José de Karene. En la comunidad de Santa Rosa de Huacaria (Oatipaeri-Matsigenka) los matrimonios suelen ser interétnicos y el antiguo sistema de parentesco ya no 
se encuentra en vigencia. Pero aún recuerdan los nombres de los patrilinajes, aunque a veces confundidos con los grupos culturales como Sapiteri ${ }^{1}$. Pienso, pues, que el sistema de parentesco ha sido sólo uno, pero que existía a través de una serie de variantes locales. El sistema de parentesco es uno de los factores que daba unidad a la sociedad Harakmbut y representa uno de los más complejos de la Amazonía peruana y del Perú.

\section{SEMÁNTICA ESTRUCTURAL VS. CRITERIOS DE USO}

Para la terminología de parentesco Harakmbut propondré un análisis componencial muy similar al de la semántica estructural. Esto requiere quizá una justificación y algunas breves aclaraciones. La semántica estructural, formalizada y "ajustada" teóricamente tuvo un éxito descriptivo inicial muy significativo y promisorio. Los avances en la descripción, usando 'rasgos distintivos' binarios en el estudio de sistemas de parentesco, taxonomias, etc. motivaron que se intentara su aplicación generalizada, primero como un componente semántico delagramática transformacional (centrada en la sintaxis) y posteriormente en la semántica generativa, (centrada en la semántica). De ese modo, la llamada etnoteoría -el estudio de los sistemas cognoscitivos étnicosingresa a la teoría lingüística general. Pero el intento de integración fracasa. Más allá de campos semánticos altamente sistematizados (como terminologías de parentesco) su aplicación se vuelve dudosa y lleva a distintas versiones o análisis posibles, sin que se pueda decidir cuál es el apropiado. Parte del fracaso se debe a las condiciones teóricas autoimpuestas: la descripción de uñ campo semántico por 'rasgos distintivos' resulta circular. Es decir, rasgos distintivos como 'humano' son a su vez objeto de análisis en otros campos semánticos. Y esto ponía en evidencia la inviabilidad de los postulados téricos.

Toda la discusión en torno a la semántica estructural llevó a muchos a una conclusión mucho más radical: la misma teoría del signo, de la cual se había nutrido desde su famosa formulación por Ferdinand de Saussure, era insuficiente. La noción de 'significado' fue atacada como una mistificación que hacía imposible ver con claridad los usos del lenguaje y las formas cómo otorgamos significado a nuestras palabras. Detrás del uso (con un sentido) de una palabra se esconde toda una praxis social con una serie de reglas - la gramática profunda. Así, por ejemplo, si damos a un niño un nombre personal, eso depende de una serie de criterios dentro de un juego de reglas sociales y públicas, que no pueden ser descritas simplemente estableciendo una relación entre el nombre y lo nombrado (como si se tratara de una especie de bautizo mágico). 
Dar un nombre personal está íntimamente ligado al sistema de parentesco vigente en la sociedad y las reglas que rigen la "herencia" de nombres, el uso y mal uso que puede dárseles. $Y$ esto puede diferir mucho en distintas sociedades. Ciertos nombres pueden estar ligados a costumbres religiosas. El significado (etimológico) puede o no jugar un papel, etc. Y todo esto es sólo una pequeñísima parte de lo que llamamos 'identidad personal'. Para describir los modos cómo conferimos 'identidad personal' tendríamos que ver cómo se usan pronombres personales, cómo estamos en capacidad de reconocer la apariencia física de una persona (y de sistematizarla en los datos de un pasaporte, las huellas digitales, etc.). Los criterios de identidad son muchos.

He escogido a propósito el caso de los nombres propios, porque en ellos el rol que juega 'el significado' suele estar reducido a un mínimo: la aplicación de un nombre está regida por una serie de criterios de uso. Pero aun en los casos en que podemos definir un 'significado', éste no es otra cosa que un resumen superficial, una etiqueta - que puede ser útil en algunos casos prácticos-pero que en ningún caso sirve como un instrumento analítico de la forma cómo conferimos sentido a nuestras palabras. Al centrar nuestra atención en la relación entre la palabra y el significado tendemos a hacer desaparecer toda la praxis social que sostiene su uso. En el caso de los nombres propios (y también de la terminología de parentesco) existe la tendencia a olvidar los usos más primarios: con el nombre llamamos a una persona o la advertimos de algún peligro, por ejemplo. Sólo posteriormente adquieren otras funciones sociales.

No es mi intención discutir las ventajas y desventajas de una semántica estructural frente a la pragmática o el análisis semántico propuesto por la filosofía del lenguaje. En el caso de una terminología de parentesco, donde el análisis estructural ya ha probado su capacidad descriptiva, éste puede ser mantenido en lo fundamental, 'si los 'rasgos distintivos' son reinterpretados como criterios de uso. Esto implica, como es de suponer, todo un cambio radical en el marco teórico. Pero para los fines prácticos que perseguimos con este artículo no presenta mayores dificultades. Habría que introducir una distinción entre 'criterios de identidad' (los criterios que definen la identidad de la persona a la que se aplica el término de parentesco) y 'criterios de aplicación' es decir, criterios que rigen la aplicación de una categoría de parentesco ya formulada. Unos ejemplos aclararán esto. Criterios deidentidad, enel caso de los Harakmbut, serían: generación, patrilinaje propio/ajeno, y sexo. Criterios de aplicación, por el contrario, serían: sexo de ego y si los interlocutores tienen o no el mismo sexo. Aplicando estos últimos criterios cambia la terminología, pero no necesariamente el grado de parentesco. Esta distinción tiene, sin embargo, tan sólo un 
valor teórico. Una jerarquización de los criterios de uso da por resultado que para llegar a una descripción adecuada es necesario combinar uno y otros criterios. Así 'sexo de ego' domina toda la terminología-es la primera distinción a hacer -, pero 'la igualdad/diferencia de sexo de los interlocutores' sólo tiene sentido después de la aplicación de criterios como generación y patrilinaje propio/ajeno. Lo que nos demuestra que la organización interna de una terminología puede seguir caminos no previsibles por un sistema descriptivo altamente sistematizado y jerarquizado.

\section{TERMINOLOGÍA Y SISTEMA DE PARENTESCO}

Un sistema de parentesco puede verse como un conjunto de reglas para "poner en acción" una terminología de parentesco. Por el contrario, una terminología de parentesco puede ser vista como el sedimento - una clasificación-producto del sistema de reglas. En ambos casos se supone una simetría entre terminología y sistema de parentesco. Esto no es estrictamente cierto, tanto en los usos cotidianos de la terminología (que pueden ser varios), como en la definición de las categorías con las que operan. En el caso de los Harakmbut es obvio que el sistema de parentesco es bastante más complejo que la terminología: mientras el sistema de parentesco opera con siete clanes, en la terminología se reflejan sólo dos y que por lo tanto debemos comprender como parientes consanguíneos y afines. Existen también otras discrepancias respecto a la definición de la clase de parientes con las que un ego puede casarse y que trataremos más adelante.

Antes de aplicar un término de parentesco, suponemos, uno debe estar en capacidad de aplicar ciertos criterios básicos, como generación, línea de parentesco, sexo, etc. Estos son los criterios que definen el uso de la palabra. Y la aplicación de esos criterios supone un conocimiento del sistema de parentesco. El hecho es sin embargo, que los términos de parentesco se aplican mucho antes que el individuo adquiera conocimientos sobre el sistema de parentesco. Así un niño es introducido al uso de términos como 'papá', 'abuelo' o 'hermana', como formas para dirigirse a ciertas personas, mucho antes de que pueda entender cómo funciona el sistema de parentesco y los criterios en que se basa. Este conocimiento lo adquiere definitivamente al momento de casarse. Y aún así, en muchos contextos cotidianos se definirá un término de parentesco en relación a otros términos (circularmente). Sólo en casos de error de aplicación puede formularse explícitamente uno de los criterios ("¿Acaso es mujer?"). "Eruir criterios" supone, por lo tanto-por regla general-un esfuerzo por recordar $y$, en última instancia, un esfuerzo analítico. (2) 


\section{EL SISTEMA DE PARENTESCO}

Llamaréal conjunto de normas que regulanel matrimonio y las relaciones entre los grupos de descendencia, "el sistema de parentesco". Se trata de un conjunto de normas conocidas a la comunidad, o al menos a un grupo de individuos que pertenecen a ella, y que por lo tanto pueden formular. Esto implica, sin embargo, que pueden darse distintas versiones de una regla y que debemos tomar en consideración, desde varias ópticas, el perspectivismo social dentro de una misma comunidad. Andrew Gray ha señalado esta necesidad, con especial énfásis en la cultura Harakmbut (Gray: 1984, p. 55). De la sociedad Harakmbut no sólo puede decirse que es objeto de variación cultural espontánea, sino quees perspectivista y que la ha internalizado y asumido. Así veremos cómo algunas reglas fundamentales del sistema de parentesco pueden ser formuladas de distintas maneras, o también ver cómo toda la organización social puede "girar en el espacio" y ser vista bajo ópticas distintas -por ejemplo desde la óptica de un hombre o una mujer. Este punto lo ha desarrollado Andrew Gray en su tesis doctoral (Gray: 1983,pp.119-123). Pero ya hemos visto también que la terminología de parentesco puede asumir, desde la perspectiva de un niño un carácter totalmente distinto.

La sociedad Harakmbut está organizada en siete clanes o líneas de descendencia masculinas (patrilinajes). Una línea de descendencia se "siente familia" y puede expresar esto de distintos modos, pero se define por los modos como se reclutan sus miembros. En el caso de los Harakmbut el mito de origen acerca del árbol Oanãmei existe en tantas versiones como clanes, con ligeras variantes codificadas. Cada clan guarda su propia versión del mito de origen. Y así sucede que la sociedad Harakmbut aun en el momento de expresar las coincidencias fundamentales de su cultura, las formula en siete versiones distintas. Es también en el mito de origen donde se señala la proveniencia de cada uno de los siete clanes:

\begin{tabular}{|c|c|}
\hline \multicolumn{2}{|r|}{ 'pava de cabeza blanca' (hooîng) } \\
\hline Iaromba & iaro 'cetico de altura', - mba 'área' \\
\hline Singperi & signpa 'palmera (sp.)', - eri 'gentilicio' \\
\hline Oandignpãnã? & \\
\hline E?mbieri & $\begin{array}{l}\text { e?-'infinitivo', mbi 'liana/cuerda', } \\
\text {-eri 'gentilicio' }\end{array}$ \\
\hline & \\
\hline
\end{tabular}


Tres nombres de los clanes no tienen "significado", pero su origen también se sienta en el mito de origen: Oandingnpãnã? con oaoa, una especie deavispa, Mãsenãoã con mbedntoktok una especiedepaucar grandey Sãoerõn con el sajino, mõkas. (Gray: 1983, pp. 25-26). En la versión recogida por mí en Shintuya, correspondiente al clan Oandign pãnã? no se menciona esto, pero los datos son conocidos.

También las ideas en cuanto a la concepción proporcionan una suerte de justificación. Para los Amarakaeri de Shintuya un niño hereda a través del semen de su padre oa-so? 'cuerpo' y oa-nõ-kireng 'alma'. El útero femenino sólo "moldea" al niño y la mujer no tiene participación en la concepción. El niño también hereda un nombre oa-ndik del patrimonio de nombres de su clan. La identidad de una persona, por lo tanto, está dada en todos sus aspectos por su pertenencia a un patrilinaje determinado. Un patrilinaje necesita de mujeres de otro clan para reproducirse, pero niega que éstas tengan una participación propia en la concepción y la reproducción. Esta idea o imagen de la concepción es, por supuesto, una ilustración de la idẹología clánica Amarakaeri, una 'ilustración gramatical', no una teoría de la concepción ${ }^{(3)}$

Aparte del orden social establecido en la "época de fundación" del mito de origen y sus ideas sobre la 'concepción', pueden dar una definición estricta del patrilinaje: "Los hijos son del padre". Este es el procedimiento como se reclutan los miembros de un clan o patrilinaje.

La norma ideal del matrimonio la expresa la noción de oaia-oaia, que significa 'quedar iguales/reciprocar'. Literalmente significa 'ambos-ambos'. Hacer oaia-oaia es el intercambio de hermanas, la forma de matrimonio preferencial. Pero oaia-oaia se aplica también al intercambio de regalos (especialmente de carne), a las luchas entre hombres por una mujer y a la guerra. En las antiguas guerras interinas se luchaba especialmente por cuchillos (siro 'machete') y se robaba mujeres. Cuando había decesos se lamentaba mucho las muertes, pero había que responder, hacer oaia-oaia, provocando este proceder a su vez con contraataque futuro, lo que llevaba a una perennización de las guerras interinas.

Oaia-oaia es, pues, una noción fundamental del pensamiento Harakmbut. El quedar pares oiguales debe regir todas las relaciones establecidas. Este orden cultural es establecido en el mito de origen: allí se prescribe que los miembros de un patrilinaje tomen sus esposas de otro linaje (oa-?en-nda)(4). El casarse con sus prupias hermanas es piken 'incesto' y es castigado con la muerte (hasta ese 
momento "la humanidad" amanecía siempre, es decir vivía eternamente). A falta máxima corresponde la pena máxima. Y con ello se introduce 'la muerte' como un evento cultural de un orden establecido por el árbol oa-nã-mei, un orden del cual se puede decir que está establecido so bre el orden natural, salvaje o prehumano cuyo rasgo principal es el incesto y la ausencia de un sistema de parentesco. Ese orden no es sólo un orden social, sino un orden cósmico, basado en la reciprocidad.

Si el intercambio de hermanas es la norma preferencial, no siempre se deja realizar. Y hoy día, con poblaciones muy reducidas después del contacto con la "civilización" es más bien rara. Una posibilidad es el intercambio diferido, otra el rapto consentido - sobre todo viable durante visitas a otra comunidad. La forma más común en Shintuya es que si a un joven "le dan mujer", él vaya a vivir a casa del suegro por un lapso aproximado de dos años, durante los cuales debe probar que puede mantener a su nueva familia, y esto significa hacer casa y chacra.

La etapa de servicio matrimonial (que no es conceptualizada como un "pago") es sentida como la prueba más difícil de su vida: la fuente de muchos problemas e inconvenientes no son sus relaciones con la joven esposa, sino las relaciones con el suegro, a cuya autoridad él tiene que someterse. Debido a la escasez de mujeres el prestigio creciente del 'suegro' ha provocado en Shintuya no sólo que muchos matrimonios fracasen durante la prueba matrimonial, sino un viraje de una virilocalidad tradicional a una fuerte tendencia hacia la uxorilocalidad.

Antiguamente todos los matrimonios eran arreglados por los padres y objeto de alianzas interclánicas. Dicen que "los acostumbraban desde chiquitos". Ante mis dudas y elaboraciones sobre la estabilidad de un tal matrimonio frente a la opción "por enamoramiento", simplemente dijeron "pero funciona". Relatan también que muchas veces se casaba un hombre ya mayor con una niñita. En esos casos la madre de la niña-esposa daba acceso sexual al potencial marido de su hija, hasta que ella estuviera madura para tener relaciones sexuales. Hoy día muchos matrimonios se realizan por enamoramiento, pero ello también requiere del consentimiento de los padres. Matrimonios forzados por los padres suelen tener serios problemas, pero el único modo de evitar el consentimiento de los padres es el rapto consentido y éste es difícil de practicar.

En cuanto al nombre que se da al 'clan propio' existe un problema. Andrew Gray menciona onju en su tesis doctoral (Gray: 1983) y onchiu en un 
artículo escrito en 1981 (Gray: 1984, p. 55)(5) Ninguna de esas palabras es reconocida en Shintuya. Mis propias averiguaciones dieron por resultado que se decía oambet o oambaet que puede analizarse así: oa - nominalizador, -mbaplural verbal (acción de varios/acción repetida), et - ser posible, y que glosan como 'mi familia'. Para Andrew Gray, sin embargo, huambet es un grupo cognático, cuyos límites no están bien definidos y que incluye: las personas del propio patrilinaje, la madre y sus hijos, la hermana de la madre (si vive en la proximidad), pero que excluye a los primos cruzados (esposas potenciales y cuñados potenciales) (Gray: 1983, p. 136). Por lo que alcanzo a comprender, entonces, la noción de huambet que Gray describe para la comunidad de San José del Karene, excluye del propio huambet a los miembros de otro clan en la generación cero (la de ego), pero los incluye en las generaciones ascendentes. Esta noción de huambet parece cubrirse con otra noción, al menos similar, usada en Shintuya: ndo?-edn harak-mbut 'mis parientes' (cercanos), que también juega un rol en la definición de reglas de parentesco. En todo caso en Shintuya se puededecir, por ejemplo: iaromba-ed noa-mbet 'la familia iaromba' y para un ego masculino se excluye que su esposa (oa-to-e) o su madre (nãng?) pertenezcan al mismo oambet, pero sí incluye explícitamente al padre (pagn) y a sus niños (oa-si?-po). Sentado así el uso del término oambet en Shintuya es equivalente al de un 'patrilinaje'.

Las diferencias terminológicas aparte, -que pueden deberse a una cierta variación cultural- podemos afirmar que el arreglo de un matrimonio (en ambos casos) no sólo es cuestión de los patrilinajes: en el arreglo participan las madres de los contrayentes también. Es decir: el "grupo de gestión" no sólo son los clanes de los contrayentes, ya que las madres (y eventualmente las madres clasificatorias) también tienen que convenir, y ellas pueden pertenecer a otros clanes.

La norma fundamental del sistema de parentesco es pues, el matrimonio entre dos patrilinajes distintos. El matrimonio preferencial por intercambio de hermanas es sólo un caso especial de esta norma. (Ver Esquema 1)

Esta norma, sin embargo, no es suficiente. Hay una segunda norma, de la cual existen también algunas formulaciones distintas.

La versiỏn más estricta de esta segunda regla es que "las madres delos que se casan no deben ser hijas del mismo padre legítimo". A ellas se refieren como ndo?-edn oaidnpo a-pagn-ên-te, literalmente como 'mis hermanas de un mismo padre', usando el término referencial a-pagn 'padre genético'. (Ver el Esquema 2) 


\section{ESQUEMA 1}

Intercambios matrimoniales entre patrilinajes
A
B
$\mathrm{C}$
D
E
F...

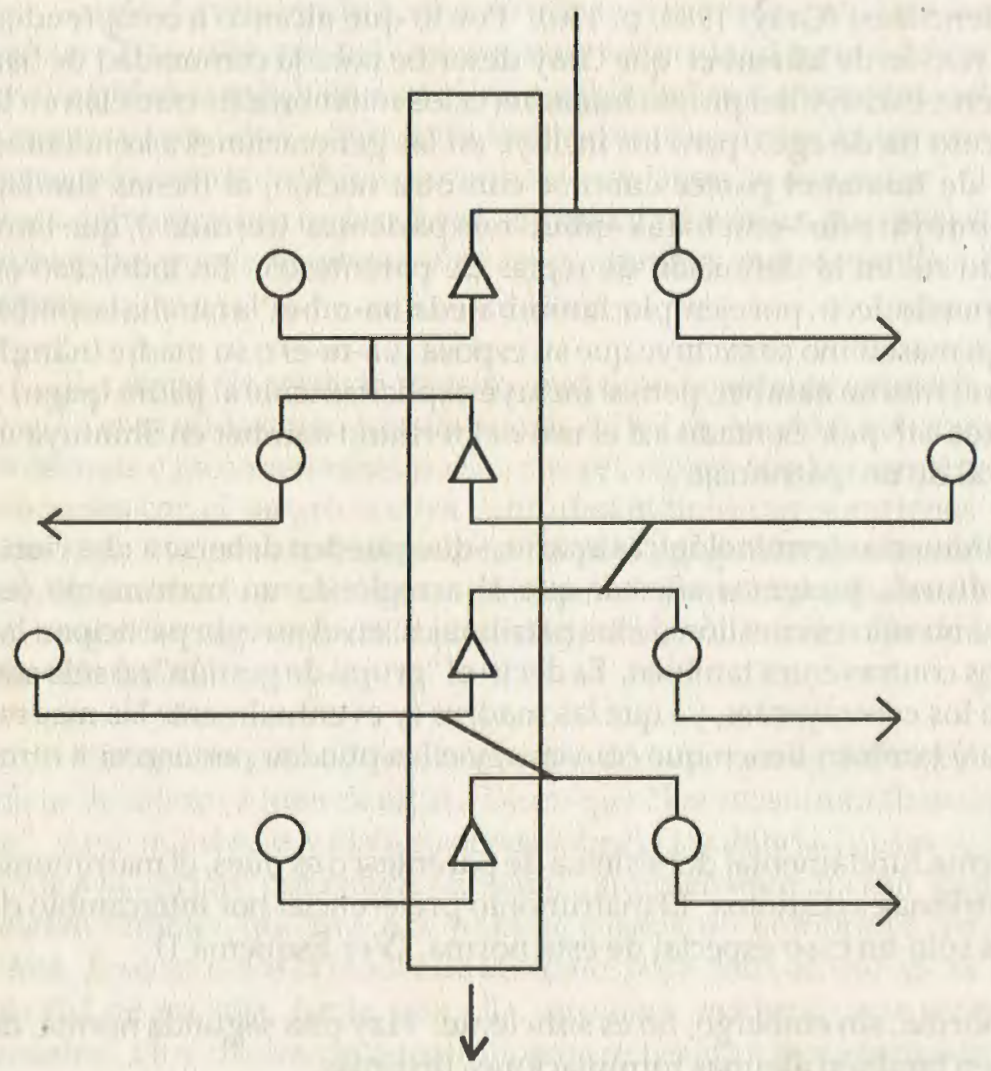

En este esquema se puede reconocer cómo un patrilinaje tiene una existencia proyectada en el tiempo: es un dador y un receptor de mujeres-mujeres de otros patrilinajes sin las cuales no podría existir; pero que a su vez no son parte del patrilinaje. 
Otra formulación, menos explícita, pero que cubre los mismos casos, es que se debe evitar matrimonios en la 'familia cercana' (ndo?-edn harak-mbut). Esta regla es más extensa que la anterior: repite la prohibición de incesto con los propios hermanos y agrega "los parientes cercanos". En realidad se trata de los hijos/as de oa-si (asign en los términos vocativos), que es la 'madre clasificatoria' o 'la hermana de la madre', sin importar con quién se haya casado y a qué patrilinaje pertenezcan sus hijos. En la versión arriba citada, sin embargo, se especifica más claramente: las 'madres clasificatorias' deben ser hijas del mismo padre genético o como dicen "padre legítimo". En un sistema de parentesco clasificatorio es difícil expresar esto con precisión. El resultado, como ya señalaba arriba, es que la expresión ndo? edn harak-mbut (Shintuya) y el término oambet (huambet) registrado por Andrew Gray en la comunidad de San José del Karene son aproximadamente coextensivos.

La existencia de esta segunda regla restrictiva plantea algunos problemas y su sentido no está muy claro. En un principio se podía pensar que esta norma había sido introducida por misioneros, a pesar de que ambas partes lo negaban. En todo caso, era extraña la intrusión de un parentesco genético en medio de un sistema y una terminología de parentesco que sólo opera con categorías clasificatorias. El hecho que Andrew Gray haya encontrado la misma norma en una comunidad sin presencia religiosa extraña hace en extremo improbable esa tesis. Además, curiosamente, la terminología de parentesco sí distingue entre padre y madre "legítimos" y los términos clasificatorios. Pero no lo hace así al definir las clases de posibles esposos (los primos cruzados). Lo que a su vez significa, que la terminología de parentesco no es del todo congruente con el sistema de parentesco. Para definir con quién uno se puede o no casar, es necesario recurrir a la generación de los padres, porque allí sí se marca un criterio genético. (Ver Gray: 1983, p. 148)(6)

Cabe especular acerca del sentido de esta norma: ¿Es un rezago del intercambio de hermanas como forma preferencial de matrimonio? ¿Se trata de evitar matrimonios consecutivos entre sólo dos clanes? ¿Tiene la sociedad Harakmbut tal horror al inces to que lo previene aún por línea femenina (a pesar de que esto no ocupa ningún lugar en su ideología de patrilinajes masculinos) (Ver Gray: 1983, p. 120). Es difícil obtener una respuesta. Lo que es siempre palpable es el horror al incesto y por ello se dice que hay que evitar matrimonios demasiados cercanos. 
Amazonía Peruana

\section{ESQUEMA 2}

\section{PROHIBICIÓN DE MATRIMONIO ENTRE HIJOS DE PRIMAS PARALELAS HIJAS DE UN MISMO PADRE GENÉTICO.}

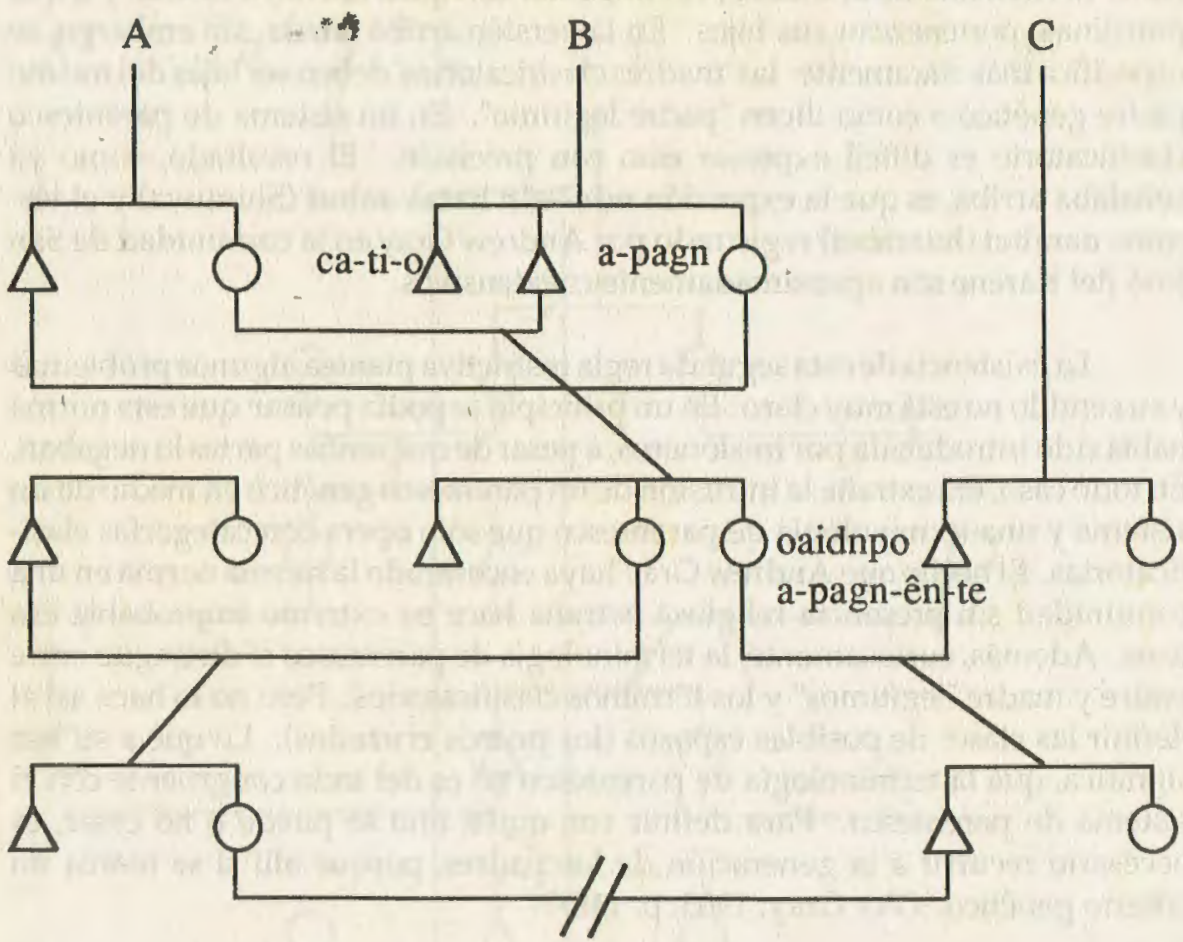

En este esquema se puede apreciar que a pesar de que los hijos de las dos hermanas paralelas pertenecen a patrilinajes distintos no pueden contraer matrimonio. 


\section{TERMINOLOGÍA DE PARENTESCO}

En Amarakaeri existen tres juegos de terminologías de parentesco: têrminos de referencia, vocativos y un tercer sistema aplicable sólo a la generación cero, de ego. Los dos primeros se refieren al parentesco en un sentido estricto y se aplican, por lo tanto, a los miembros del propio patrilinaje y a los parientes afines (el patrilinaje del esposo/a). El resto es no-pariente y queda fuera de la terminología de parentesco. La terminología de parentesco opera por eso con sólo dos líneas dedescendencia, mientras queel sistema de parentesco refleja así los términos reales de las alianzas (y el modelo ideal del intercambio de hermanas), mas no la estructura social en su cabalidad. El tercer sistema suele tener un uso más amplio. A parte.de los 'hermanos' y 'cuñados' reales se aplica a todos los miembros de la sociedad, que de ese modo pueden escoger entre una relación más cercana o distante, a pesar de ser literalmente no-parientes. Este es el parentesco ficticio.

Para describir los términos de referencia es necesario introducir los siguientes criterios: sexo de ego, generación, patrilinaje, sexo del referente, sexo dispar y consanguinidad. Estos mismos criterios son aplicables a los términos vocativos, que por lo general se cubren con los de referencia. La excepción son los vocativos para padre y madre clasificatorios. No existen, porque sería considerado impropio dirigirse a ellos con otra palabra distinta que simplemnte 'padre' o 'madre' (términos de respeto y cariño). El tercer sistema introduce un criterio nuevo: la diferencia de edad. Entre hermanos mayores y menores se dirigen unos a otros usando términos distintos. Lo mismo es cierto para las hermanas y para las relaciones entre "cuñados".

La terminología de parentesco exige algunos comentarios. En primer lugar, es obvio el carácter funcional de la terminología. Allí donde sirve para establecer las reglas matrimoniales, en la generación de ego y la generación de sus padres, es mucho más específica que en los extremos, la generación de abuelos y nietos, donde muchos criterios no encuentran aplicación y por lo tanto los términos de parentesco son más generales.

Una comparación con la terminología de parentesco, tal como la constata Andrew Gray para la comunidad de San José del Karene arroja que existen algunas diferencias terminológicas, pero que a pesar de ello se transluce que el sistema de parentesco y los criterios en que se basa son los mismos. Ladiferencia más importante es que Gray resalta la diferencia de 'sexo de ego' en desmedro de otro criterio: la igualdad/diferencia de sexo entre el hablante y el referente.(7) 
Existen algunos términos de'parentescóno incluidos èn el esquema. En primer lugar 'esposo/a' que se dice oa-to-ê (nominalizador - con/bajo -haber). El verbo e?-to-ê significa 'tener'. 'Esposo/a' se puede glosar, por lo tanto como 'la persona que tengo'. Oa-to-ê se usa en lugar de oa-timbui una vez unidos en matrimonio. Oa-si?-po significa 'niño/a'. No es propiamente un término de parentesco, pero ndo?-edn oa-si?-po se usa por 'mis niños/hijos'. Oa-iet significa 'mujer', pero es usado también por 'hermana'.

\section{DISCUSIÓN DE LOS CRITERIOS}

Sexo de ego. De acuerdo al sexo de ego se reorienta toda la terminología. Si se comparan los Esquemas 3 y 4 se constatará fácilmente que una serie de términos están invertidos. Para un ego masculino oaidnpo es de sexo femenino; para un ego femenino es de sexo masculino. Lo mismo es cierto para oa-timbui. Oa-oẽoẽ 'cuñado' es un término de uso sólo para ego masculino, teoeng lo usan sólo entre mujeres. En la generación de los hijos/sobrinos (-1) para un ego masculino sus hijos (siõn) son de su propio patrilinaje, para ur ego femenino pertenecen al patrilinaje del esposo. Y así toda la terminología se invierteen esta generación. Si la inversión de sexo en el referente para las generaciones 'cero' $y^{\prime}+1$ ' se puede explicar recurriendo a otro criterio: la identidad/diferencia de sexo entre el referente y el hablante ('sexo dispar'), esto no es el caso, para el cambio de regla de descendencia y por lo tanto es necesario mantener 'sexo de ego' como un criterio básico.

'Generación. La 'generación' es un criterio que permite una graduación, que abarca cinco (5) generaciones distintas: +2 (generación de abuelos), +1 (generación de padres), $O$ (generación de ego), -1 (generación de hijos), -2 (generación de nietos). La graduación general está autocentrada en ego.

Patrilinaje propio/ajeno. De acuerdo a este criterio se diferencia sólo entre el clan propio de ego (indexado como' 't') y el clan del esposo/a. En el caso que este criterio no se aplique, es decir si el término de parentesco no hace la đistinción entre patrilinajes, éste se marca con ' 0 ' (cero). Este es el caso, por ejemplo para oa-iaio 'nieto' o 'abuelo/a'.

Sexo Masculino. Este criterio se refiere al sexo del referente y no del hablante. Es también un criterio esencial a todas luces. He indexado 't' para sexo masculino, '-' para femenino, y '0'cuando no se aplica. 


\section{ESQUEMA 3 \\ TERMINOLOGIA DE PARENTESCO}

Sistema (a): términos de referencia

EGO masculino

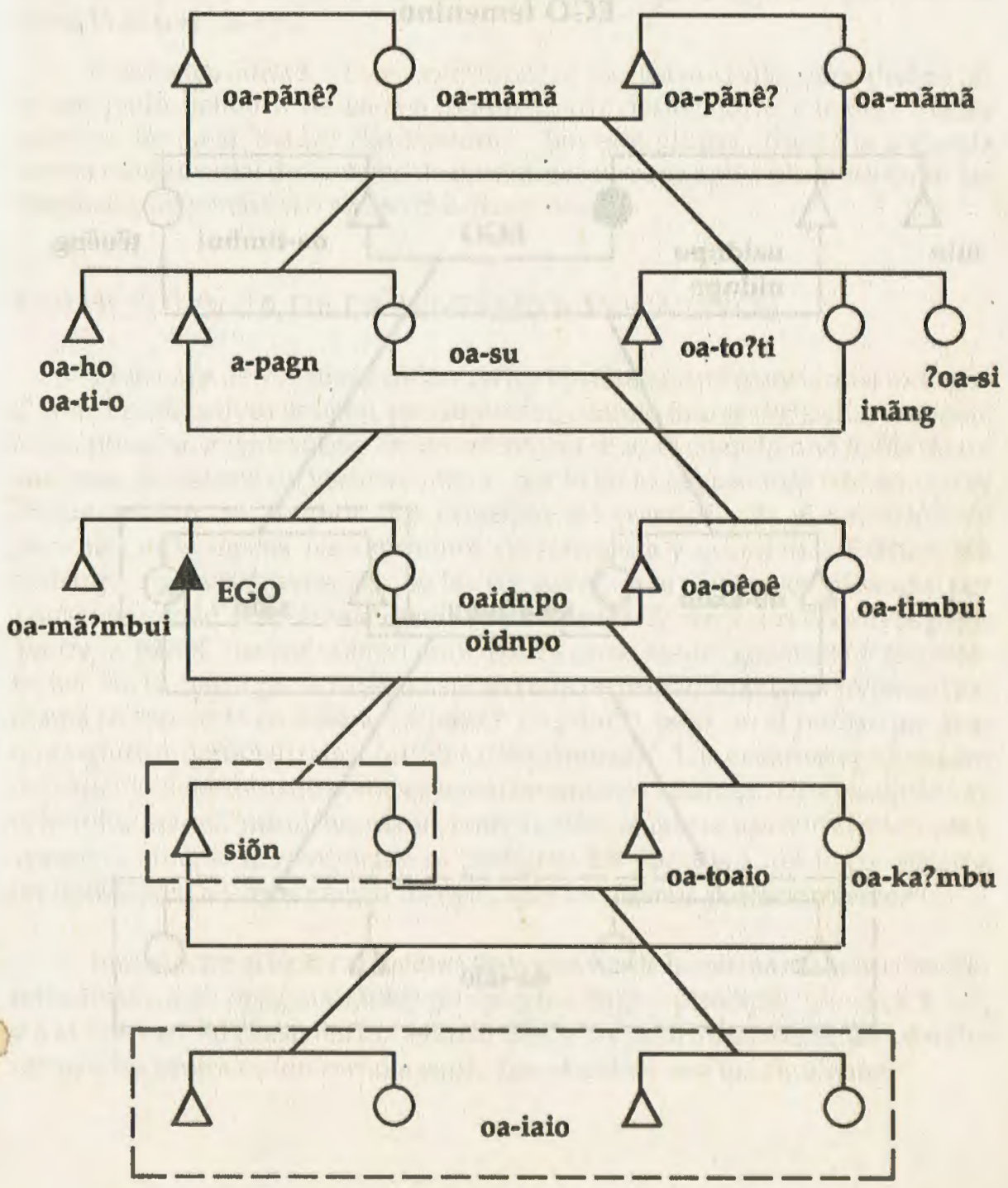




\section{ESQUEMA 4}

\section{TERMINOLOGÍA DE PARENTESCO}

Sistema (a): términos de referencia EGO femenino




Sexo dispar. Este criterio sirve para marcar aquellos términos de parentesco que se usan entre personas de distinto sexo ('t') o exclusivamente entre personas del mismo sexo ('-'). De este modo recojo el criterio "entre mujeres", "entre hombres" y "sólo entre hombre y mujer". Así, por ejemplo oamã?mbui se usa sólo entre hombres y oaidnpo entre hombres y mujeres- lo que aclara muy bien, por qué el sexo del referente cámbia para algunos términos de acuerdo al sexo de ego.

Consanguinidad. Este criterio sirve exclusivamente para distinguir apagn 'padre genético' de oa-ti-o/oa-ho 'padre clasificatorio' y inãng? 'madre genética' de oa-si 'madre clasificatoria'. Sin este último criterio la segunda norma fundamental del sistema de parentesco no sería aplicable, pues todas las categorias de parentesco serían clasificatorias.

\section{TERMINOLOGÍA DE PARENTESCO: VOCATIVOS}

El sistema de vocativos difiere de los términos de referencia ante todo por el uso. Los vocativos se usan, por supuesto, cuando uno se dirije directamente a una persona, mientras que los de referencia se usan cuando uno habla de un pariente. El sistema de vocativos tiene, por lo tanto, un uso más frecuente y es el que primero se aprende. En principio los criterios y la clasificación de parientes es la misma para términos de referencia y vocativos. Existen, sin embargo, algunas diferencias: en los vocativos no se distinguen parientes por 'consanguinidad' (ese criterio queda fuera de uso). Es decir, los vocativos pagn 'padre' y nãng? 'madre' cubren tanto padre como madre genéticos y clasificatorios. En la mayor parte de los casos se trata inclusive del mismo término (oamãmã se convierte en mãmã, oa-pãnê? en pãnê?), pero sin el prefijo oa- o aque significa 'nominalizador/artículo determinado'. Los vocativos prescinden del artículo determinado como es usual en muchos idiomas. Una excepción es el término oa-mã?mbui 'hermano, entre hombres', que se usa como referentey vocativo, aunque normalmente se prefieren los vocativos del tercer sistema (aplicable sólo a la generación de ego), que trataremos posteriormente. ${ }^{(8)}$

Introduciré al lector al sistema de vocativos de la misma manera como fui introducido a él: presentándolos por parejas, bajo el principio: qué dice $X$ a $Y$, y a la inversa. Al presentarlo, avanzo desde las posiciones extremas (abuelonieto) a las centrales (en torno a ego). Los términos son los siguientes: 
Amazonía Peruana

\section{ANÁLISIS SEMANTICO DE LOS TÉRMINOS DE REFERENCIA}

$$
\text { generación patrilinaje sexo sexo } \begin{gathered}
\text { sepio masculino dispar consanguinidad } \\
\text { propio }
\end{gathered}
$$

\begin{tabular}{lccccc} 
oa-pãnê & +2 & 0 & + & 0 & 0 \\
oa-mãmã & +2 & 0 & - & 0 & 0 \\
oa-ho/oa-tio-o & +1 & + & + & 0 & 0 \\
a-pagn & +1 & + & + & 0 & + \\
oa-su & +1 & + & - & 0 & 0 \\
oa-to?ti & +1 & - & + & 0 & 0 \\
inãng? & +1 & - & - & 0 & + \\
oa-si & +1 & - & - & 0 & - \\
oa-mã?mbui & 0 & + & + & - & 0 \\
mũn & -0 & + & + & - & 0 \\
oaidnpo/oidnpo & 0 & + & 0 & + & 0 \\
oa-oẽoẽ & 0 & - & + & - & 0 \\
tẽoẽng & 0 & - & - & - & 0 \\
oa-timbui & 0 & - & 0 & + & 0 \\
siõn & -1 & $+(\ldots)$ & 0 & 0 & 0 \\
oa-toaio & -1 & $-(+)$ & + & 0 & 0 \\
oa-ka?mbu & -1 & $-(+)$ & - & 0 & 0 \\
oa-iaio & -2 & 0 & 0 & 0 & 0 \\
\hline
\end{tabular}

Entre paréntesis '(...)' los valores insertar para un ego femenino 


\section{JERARQUÍA ENTRE LOS CRITERIOS SEMÁNTICOS}

\begin{tabular}{|c|c|c|c|}
\hline generación & & & \\
\hline
\end{tabular}

$$
+2
$$

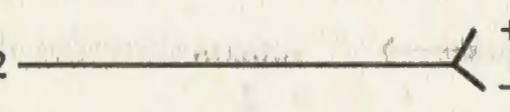

oa-pãnẽ?

oa-ho/oa-ti-o
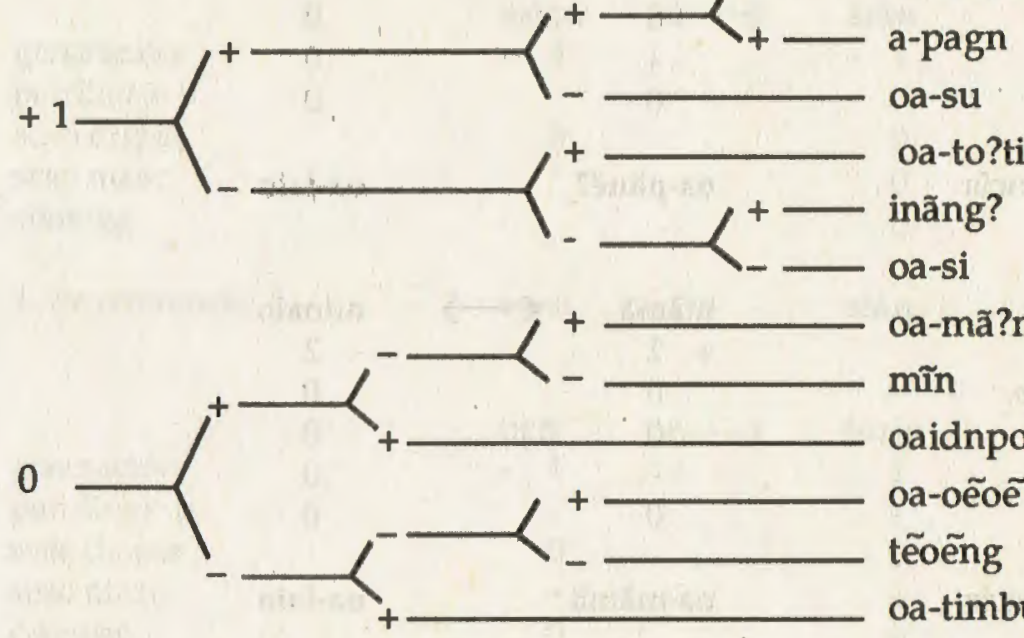

oa-ma?mbui

mĩn

oaidnpo / oidnpo

oa-oе̃oẽ

tẽoẽng

oa-timbui

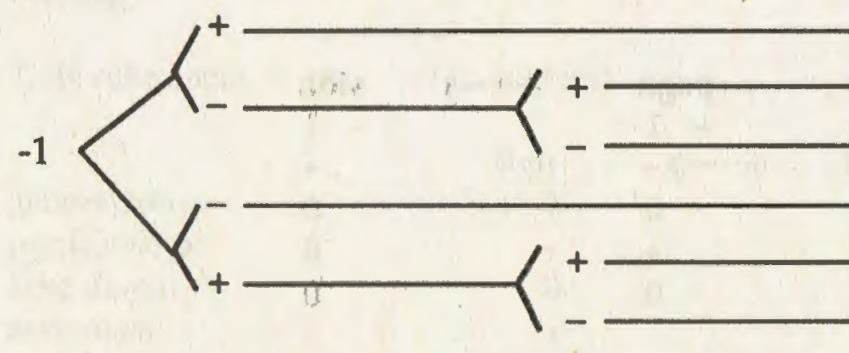

siōn

oa-toaio

oa-ka?mbu

siōn*

oa-toaio

oa-ka?mbu

$-2$

oa-iaio

' ' = Variantes para ego femenino 
Amazonía Peruana

\section{TERMINOLOGÍA DE PARENTESCO}

Sistema (b): vocativos.

\section{EGO masculino.}

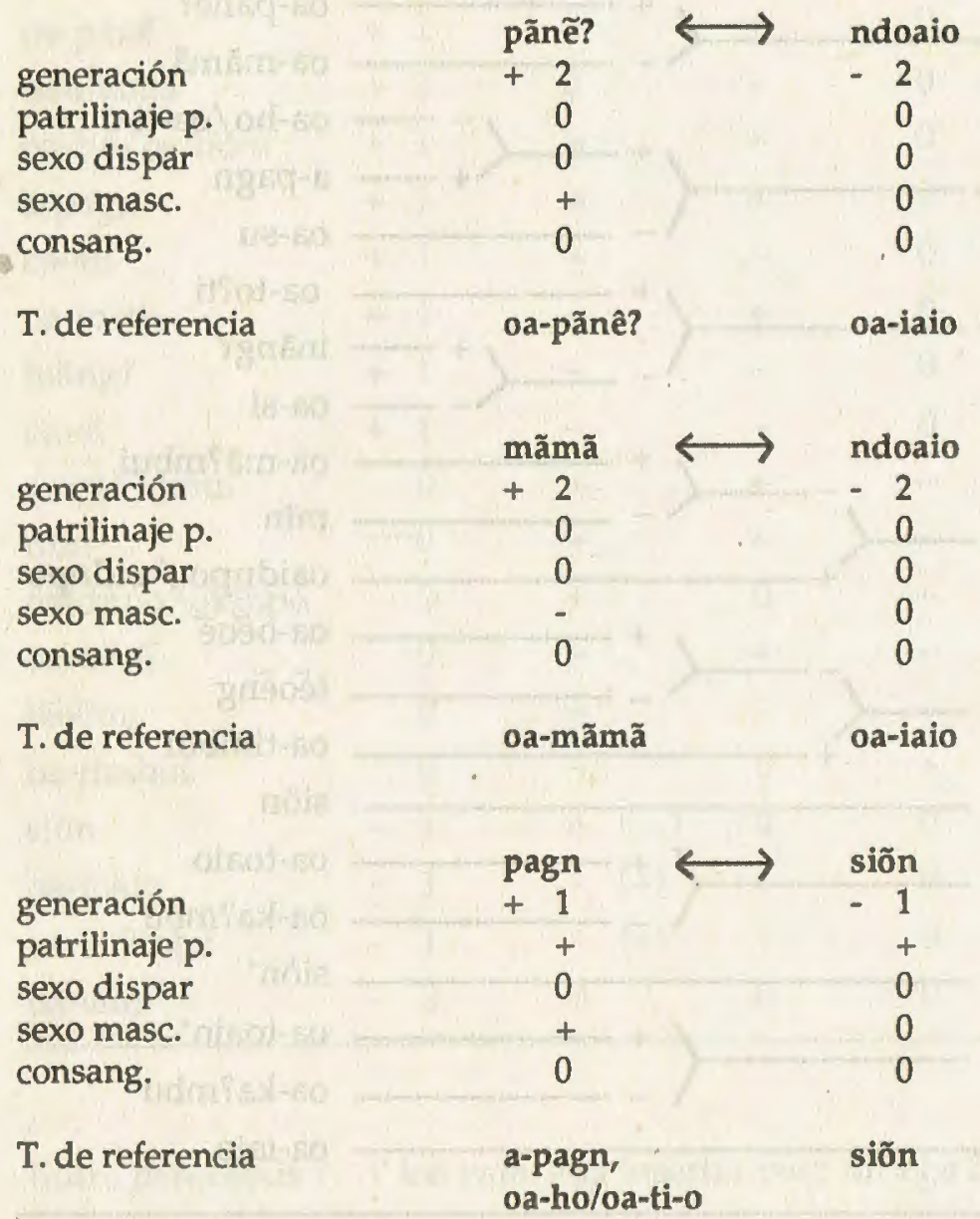


generación

patrilinaje $p$.

sexo dispar

sexo masc.

consang.

T. de referencia

generación

patrilinaje $\mathbf{p}$.

sexo dispar

sexo masc.

consang.

T. de referencia

generación

patrilinaje $\mathbf{p}$.

sexo dispar

sexo masc.

consang.

T. de referencia

generación

patrilinaje p.

sexo dispar

sexo masc.

consang.

T. de referencia

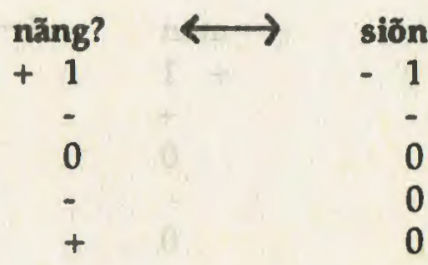

inäng?

siỡn

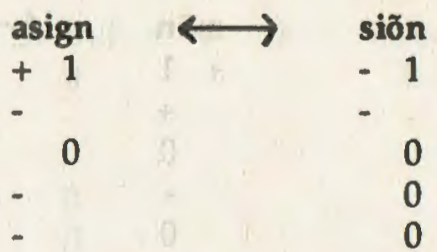

oa-si

siōon

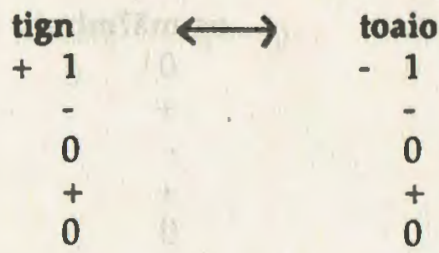

\section{oa-to?ti oa-toaio}

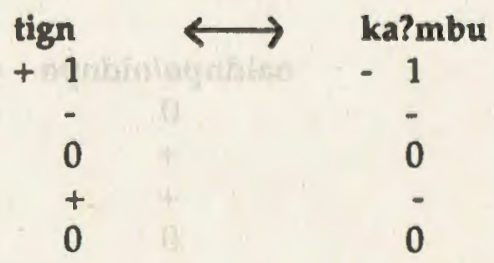

oa-to?ti

oa-ka?mbu 
generación patrilinaje $p$. sexo dispar sexo masc. consang.

T. de referencia

generación patrilinaje $p$. sexo dispar sexo masc. consang.

T. de referencia

generación patrilinaje p. sexo dispar sexo masc. consang.

$\mathrm{T}$. de referencia

generación patrilinaje $p$. sexo dispar sexo masc. consang.

T. de referencia

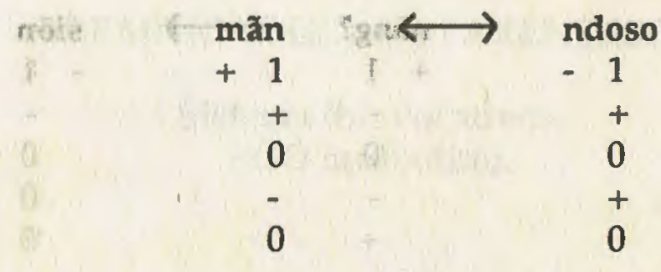

oa-su

oa-toaio

$$
\begin{array}{r}
\text { mãn } \\
+\quad 1 \\
+ \\
0 \\
- \\
0
\end{array}
$$

oa-su

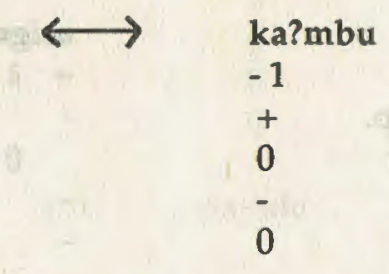

oa-ka?mbu oa-mã?mbui

0

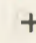

$-$

$+$

0

oa-ma?mbui

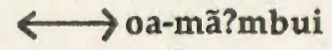

0

$+$

$-$

$+$

0

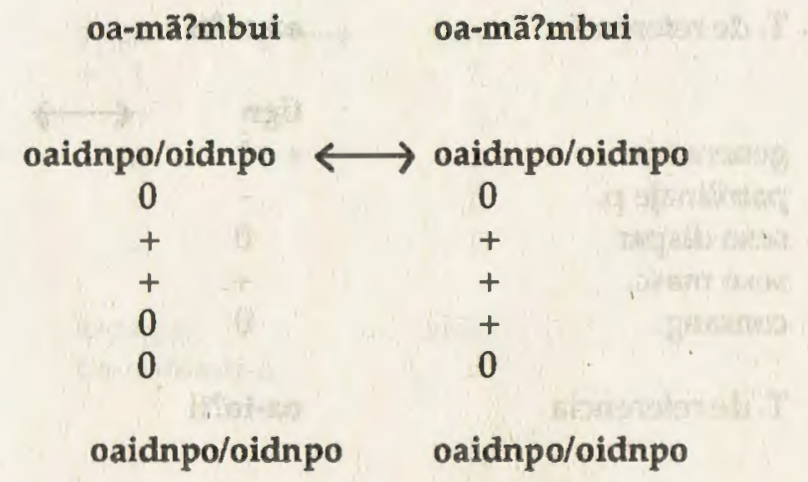


generación

patrilinaje $p$.

sexo dispar

sexo masc.

consang.

T. de referencia

generación

patrilinaje $p$.

sexo dispar

sexo masc.

consang.

T. de referencia

generación

patrilinaje $\mathrm{p}$.

sexo dispar

sexo masc.

consang.

$T$. de referencia

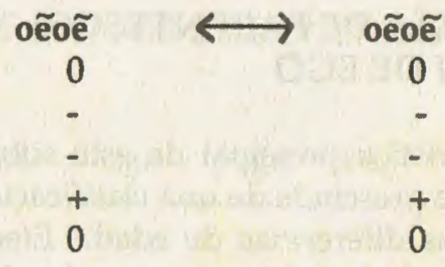

oa-oeoe

oa-oeoe

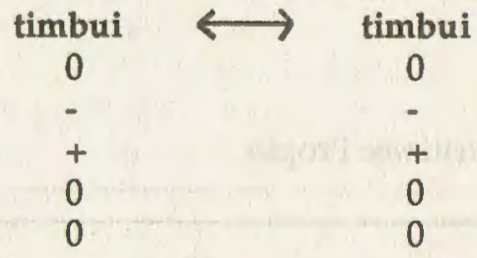

oa-timbuy

oa-timbui

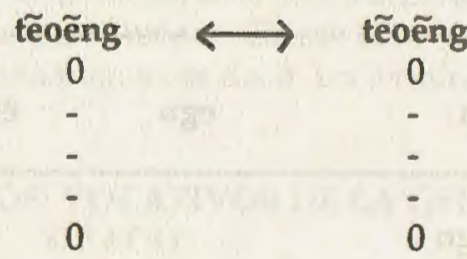

tẽoẽng

tผ้อักร 


\section{TERMINOLOGÍA DE PARENTESCO: VOCATIVOS DE LA GENERACIÓN DE EGO}

La característica principal de este subsistema de la terminología de parentesco es que prescinde de una clasificación generacional e introduce un nuevo criterio: las diferencias de edad. Efectivamente, los vocativos para 'hermanos' y 'cuñados' cambian de acuerdo a la persona a la que uno se dirije, dependiendo esto de las diferencias de edad. Cuando la persona es mayor que el hablante, marco este criterio con ' + ', cuando es menor con ' - ' y donde no se aplica o está neutralizada con ' 0 '.

Patrilinaje Propio Patrilinaje Ajeno

\begin{tabular}{lllll}
\hline & Mayor & Menor & Mayor & Menor \\
\hline ft min & tõn & ẽng? & eng? \\
\hline $0 \%$ egn & egn & ẽn? & ẽn?tipo \\
\hline 90 pogn & & & \\
\hline
\end{tabular}

También para este subsistema de la terminología podemos postular un conjunto de criterios que se usan en su aplicación, así como una jerarquía entre los criterios. 


\section{ANÁLISIS SEMÁNTICO: VOCATIVOS DE LA GENERACIÓN DE EGO}

\begin{tabular}{|c|c|c|c|c|c|c|c|}
\hline riterios & mĩn & tõn & egn & pogn & eng? & en? & ẽn?tipo \\
\hline 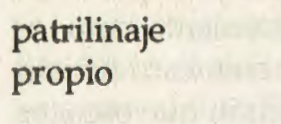 & + & + & + & + & & & \\
\hline$x c$ & - & - & te. & + & - & - & \\
\hline - $2(4 x-1$ & & - & + & + & & & \\
\hline e edad (mayor) & + & 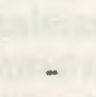 & 0 & + & 0 & + & - \\
\hline
\end{tabular}

Nótese que en el esquema propuesto el término pogn está caracterizado por los criterios 'sexo dispar', marcado como 't' y 'sexo masculino', también marcado como ' + ', lo que significa que sólo la hermana menor puede dirigirse al hermano mayor como pogn. No existe un vocativo exactamente inverso que use el hermano mayor con la hermana menor. En ese caso se puede usar por ejemplo, oaidnpo-si?-po 'hermana menor'; es decir, un término derivado.

\section{JERARQQUIA DE CRITERIOS: VOCATIVOS DE LA GENERACIÓN DE EGO}

$\begin{array}{cccc}\text { patrilinaje } & \text { sexo } & \text { sexo } & \text { diferencia de } \\ \text { propio } & \text { masc. } & \text { dispar } & \text { edad (mayor) }\end{array}$

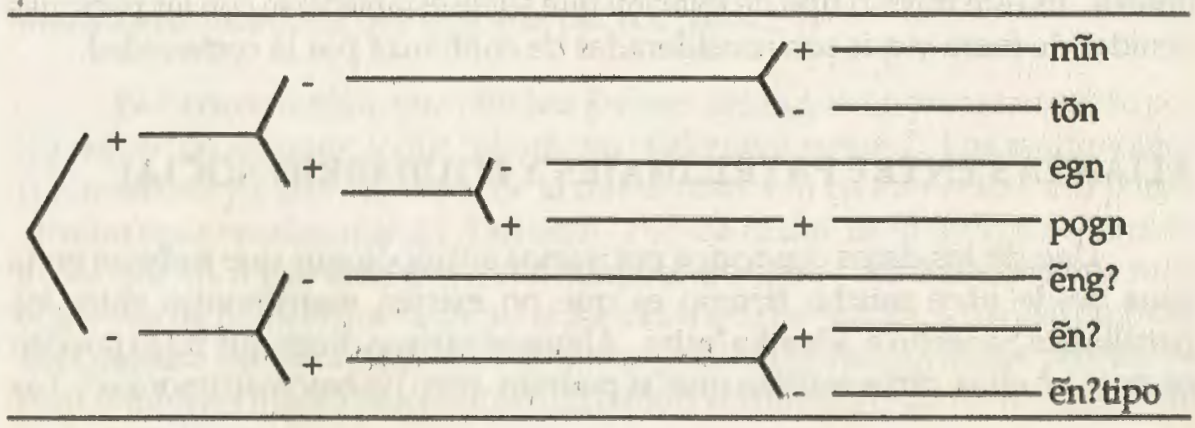




\section{EL PARENTESCO FICTICIO}

En la terminología de parentesco se encuentran "fuera del sistema" todos aquellos miembros de la sociedad Harakmbut que no son considerados en un sentido estricto parientes - los miembros del patrilinaje propio y los parientes afines. A esos no-parientes, sin embargo, se les ofrece un tratamiento 'como si' fueran parientes. Se entabla, por lo tanto una relación de parentesco ficticio, cuyo grado de cercanía ('hermanos') o lejanía ('cuñado') tendrán que escoger. Esta extensión de la terminología de parentesco a todos los miembros de la sociedad Harakmbut me parece importante; porque es el primer inicio de la aplicación de un patrón lógico: el de dos mitades que intercambian mujeres, como patrón o forma para establecer relaciones. Elevado a patrón de pensamiento es posible 'pensar' éstas y muchas otras relaciones con la idea fundamental de intercambio equilibrado, queasíse convierte en un rasgo característico de una forma de pensamien to - $y$ también de la praxis de conducción de relaciones entre grupos humanos, entre la sociedad y la naturaleza (de la que se sustenta), etc.

Algunos ejemplos de parentesco ficticio esclarecerán el caso. Un informante pertenece al clan Oandignpãnã?, su antigua mujer - de la que vive separado - pertenece al patrilinaje ?idnsika?mbu. Un hombre mayor y de respeto en la comunidad pertenece al clan Iaromba, es literalmente su no-pariente, pero se dirije a mi informante como ẽn? tipo 'cuñado menor', y él a su vez lo llama ẽn? 'cuñado mayor'. Con otro miembro de la comunidad, un ?idnsika?mbu, se tratan mutuamente de egn o hegn 'hermano', a pesar de que podrian tratarse de 'cuñados' por la ex-esposa de mi informante. Cuando hay un declive de edad mayor puede escogerse la fórmula pagn/sión 'padre/hijo', pero lo más usual es que para estas relaciones se escojan vocativos de la generación de ego. El parentesco ficticio representa, pues, un campo libre, donde los miembros de la sociedad pueden escoger el tipo de relación que desean. Es este mismo tipo de relación que suele establecerse con las personas venidas de fuera y que son consideradas de confianza por la comunidad.

\section{ALIANZAS ENTRE PATRILINAJES Y EQUILIBRIO SOCIAL}

Uno de los datos conocidos por varios antropólogos que trabajan en la zona desde hace mucho tiempo es que no existen matrimonios entre los patrilinajes Sãoẽrôn ẽ Idnsika?mbu. Algunos nativos dicen que no se pueden casar entre ellos, otros señalan que "sí podrían, pero no hay matrimonios". Las 
razones no son claras y la mayoría de nativos en Shintuya no tiene ninguna explicación. El trabajo etnográfico de Andrew Gray en la comunidad de San José del Karene a abierto, sin embargo, una nueva brecha de investigación, que aquí quisiera resumir muy brevemente.

Los siete patrilinajes se dividen en dos grupos por su orientación simbólica hacia el río o hacia el bosque: Iaromba, Mãsẽnãoã y Oandignpãnã? se orientan al río y Singperi, ?idnsika?mbu, Sãoẽrõn y E?mbieri al bosque.(9) De ello derivan ciertos privilegios de caza y de conexión con espíritus de animales que rigen esas actividades. Se considera también que en cada poblado no deben existir más de cuatro patrilinajes, que se dividen en dos grupos, uno orientado al río y el otro al bosque. Dentro de cada grupo existe una alianza, por la cual los clanes que son minoritarios numéricamente se someten al clan dominante pretendiendo ser parientes y al menos usualmente evitando matrimonios entre ellos. Aplicado esto a Shintuya, por los mismos datos que proporciona Gray, significaría que los clanes dominantes son Iaromba e ?idnsika?mbu y los patrilinajes Mãsẽnãoã y Oandignpãnã son los aliados de los Iaromba, mientras que Singperi, E?mbieri y Sãoẽrõn son los aliados delos Idnsika?mbu. Al parecer de Gray este sistema de aliarizas logra un equilibrio entre las dos partes, que no son 'mitades' en un sentidoestricto, pues su configuración interna puede variar. Es posible, inclusive, que se den matrimonios al interior de una de las partes-llevados sobre todo por la baja demográfica que sufren hoy día y que hace muy difícil encontrar una pareja viable para un individuo.

Hasta qué punto el modelo de San José del Karene se aplica a Shintuya es difícil de aseverar. Por lo general la división entre clanes orientados al río y al bosque parece respetarse, aunque existe al menos una excepción (Iarombal Oandignpãnã). El uso de la terminología de parentesco ficticio tampoco corrobora el modelo (Iaromb y Oandignpana? deberían tratarse de 'hermanos' y se tratan de 'cuñados', etc.). Pero todo esto requiere de una investigación mucho más profunda que está aún por realizarse. (10)

Es cierto también, que muchos jóvenes dicen que no piensan regirse por las reglas "de antiguo" y que "ahora con cualquiera nomás". Los matrimonios con mestizos y personas fuera de la comunidad van en aumento y eso puede terminar por erosionar todo el sistema. Por esa razón, en Shintuya, se trata de evitar que las mujeres se casen con hombres de fuera - eso desarticularía todo el sistema de patrilinajes - aunque sí permiten que los hombres traigan esposas. Esta defensa legítima de su sociedad ocasiona, sin embargo, serios problemas con las mujeres que ya han establecido familia con hombres de fuera y que están 
normalmente expulsadas de la comunidad, pero que siguen frecuentándola y que tienen una existencia al margen de ella.

No está tampoco muy claro qué vigencia retrospectiva tendría el sistema de alianzas puesto al descubierto por Gray. Se supone que antes del "contacto" en cada casa comunal (llamadas hak anteriormente y ahora hak-tõnê 'casa mayor') vivía un solo patrilinaje, y que los intercambios matrimoniales se realizaban entrelas distintas hak. No me ha sido posible averigüarsi ese sistema de alianzas también se daba entre las hak o si es un sistema posterior, creado a raíz de su reunión en misiones y poblados mayores.

Un punto interesante por resaltar, una vez más, es que todo este esfuerzo por establecer un orden bipartito de intercambios obedece al mismo patrón lógico de intercambios y equilibrios que ya hemos establecido - un orden fundamental trazable hasta el mito de origen. Es quizá también comprensible que estableciendo un orden bipartito (aunque no siempre sea aplicable estrictamente) se da una viabilidad política a las alianzas matrimoniales. Quiero decir con ello que resulta más fácil llegar a acuerdos matrimoniales con unidades mayores organizadas que en un enjambre de relaciones posibles entre los siete patrilinajes. No debemos olvidar tampoco que de ese modose pueden establecer relaciones simbólicas que por una red múl tiple de ecos establecen toda una red de conexiones: estructura social/estructura de la naturaleza (río/bosque)/ los espíritus del río y del bosque/ la incentivación y las restricciones de la caza. Y esto trae consigo una enorme ganancia, pues crea una 'forma de vida' y establece una ética.

\section{PARENTESCO Y EL PERSPECTIVISMO SOCIAL}

Hemos visto el sistema de parentesco como un conjunto de reglas para reclutar parientes - cuya clasificación está depositada en la terminología de parentesco. Pero el sistema de parentesco es multifuncional en una sociedad en la cual la mayoría de las relaciones gira en torno al sistema de parentesco o en todo caso a los criterios de uso de la terminología de parentesco.

Esees el caso, por ejemplo, con la división sexual del trabajo o también con el uso de nombres propios. Estos conforman un reservorio de cada patrilinaje, pero un individuo cambia de nombre a través de su vida. Los hombres cambian de nombre durante el rito de pasaje de la adolescencia para estar aptos para el matrimonio.(11) Los shamanes, llamados oa-iorok-eri 'soñador', también cam- 
bian de nombre cuando "la madre" de una especie "los para porque hay abuso". Así dicen: "siempre se cambian de nombre". Los nombres propios son guardados como un secreto -muy pocos lo saben, porque eso significa entregar poder sobre uno. En su lugar usan apodos. Pero también estos son usados con reserva frente a personas extrañas a la comunidad. El término de parentesco es por ello la forma más usual de dirigirse a una persona y la que primero aprenden los niños. La aplicación de los términos de parentesco también cambia, por supuesto, cuando alguna persona altera su estatus (por matrimonio o disolución, nacimiento o fallecimiento), y todo el uso de la terminología tiene que girar y ajustarse a este hecho. En realidad, tanto los nombres propios como la terminología de parentesco funcionan como sistemas deícticos distintos, pero engarzados el uno al otro.

La división del trabajo sigue el usual sistema de división de roles por sexo y edad. El grupo de trabajo por excelencia -aquel al que se recurre para actividades mayores como limpiar y quemar un área de cultivo o construir una casa - es el grupo de hermanos de un mismo patrilinaje.

El sistema de parentesco también puede ser visto como una serie de normas cuyo objetivo es regular la interrelación entre los sexos y es aquí donde podemos ver que hombres y mujeres pueden tener una visión opuesta, pero a su vez complementaria de lo que es un patrilinaje y la estructura social.

Entre los Harakmbut todo en la esfera sexual es muy tenso. Un joven que encuentra a una muchacha la saludará sin levantar la vista. Ella se abstendrá de sonreirle, porque ello podría ser interpretado como una posibilidad de establecer una relación personal. Aún parejas casadas no suelen intercambiar en público ningún tipo de caricias - ni siquiera un gesto que devele intimidad. Si unjoven desea pretender oficialmenteuna muchacha, lo hará llevando presentes de carne. Ella puede corresponder tejiendo y obsequiando bolsas de cetico o con pescado. Una vez "arreglado" un matrimonio no existe ninguna ceremonia especial. El marido se muda a casa del suegro y empieza a convivir con ella. El suegro y cada miembro del patrilinaje de la esposa reciben de regalo una flecha adornada con plumas. El regalo de matrimonio se llama tindoi o también tindoia (212) Entonces se inicia para el recién casado la difícil etapa de su servicio matrimonial. A pesar de que están previstos sólo dos años, ese servicio suele prolongarse mucho más. La pareja quizá haga "cocina aparte", pero con la construcción de una casa se toman tiempo, que finalmente se convierte en uxorilocalidad. Este es un beneficio para el suegro, que no sólo acrecienta su prestigio sino que se asegura la provisión de carne. El hombre es visto sobre 
todo como un proveedor de carne de monte, y la caza es su actividad principal y también el eje central del shamanismo.

Esta tendencia hacia la uxorilocalidad compensa la estructura clánica y la ideología netamente masculina delos patrilinajes. Un patrilinaje se proyecta en el tiempo: las mujeres van y vienen pero de generación a generación el patrilinaje subsiste. Desde un punto de vista femenino, el grupo local femenino permanece en un solo lugar, mientras que son los maridos los que van y vienen. Los patrilinajes de esposos e hijos cambian, pero el grupo de residencia permanece. Visto desde esa perspectiva la organización social tiene menos que ver con los patrilinajes que con el grupo de residencia y el eje "abuela-hija-nieta".(Ver esquema 3 para ilustración de este punto de vista y contrastarlo con el esquema 1 , el punto de vista masculino).

Es a esta divergencia de perspectivas sociales a las que señalaba Andrew Gray en un árticulo publicado en esta misma revista y que me parece acertada y que los nativos de Shintuya aceptan también como verdadera. Pero también reconocen que son dos posiciones abstractas. También las mujeres tienen que pensar en los patrilinajes (si no, no pueden casar a sus hijos, por ejemplo), y los hombres se insertarán en el grupo de residencia para todas las actividades cotidianas, caza, pesca, etc., y en algunos casos eso lleva a un alejamiento de su propio patrilinaje. Lo más importante es, sin embargo, que resaltan la complementariedad de ambas visiones. No las ven como opuestos irreconciliables, sino como puntos de vista por los que se puedeoptar. Debemos reconocer también que ambas visiones son producto de un mismo juego de reglas (hacer oaia-oaia, etc.) y quelos esquemas distintos son sólo un arreglo diferente de los símbolos en el espacio.

El hecho que un patrilinaje se proyecteen el tiempo se ha acentuado desde el momento en que ya no están reunidos en un hak-tõné? 'casa-mayor': los miembros de un patrilinaje pueden estar dispersos por muchas localidades. Esta proyección en el tiempo tiene su reflejo en la estructuración del ciclo de vida para el hombre y la mujer. El ciclo de vida masculina está mucho más estructurado: 
ESQUEMA 5

Uxorilocalidad y Descendencia

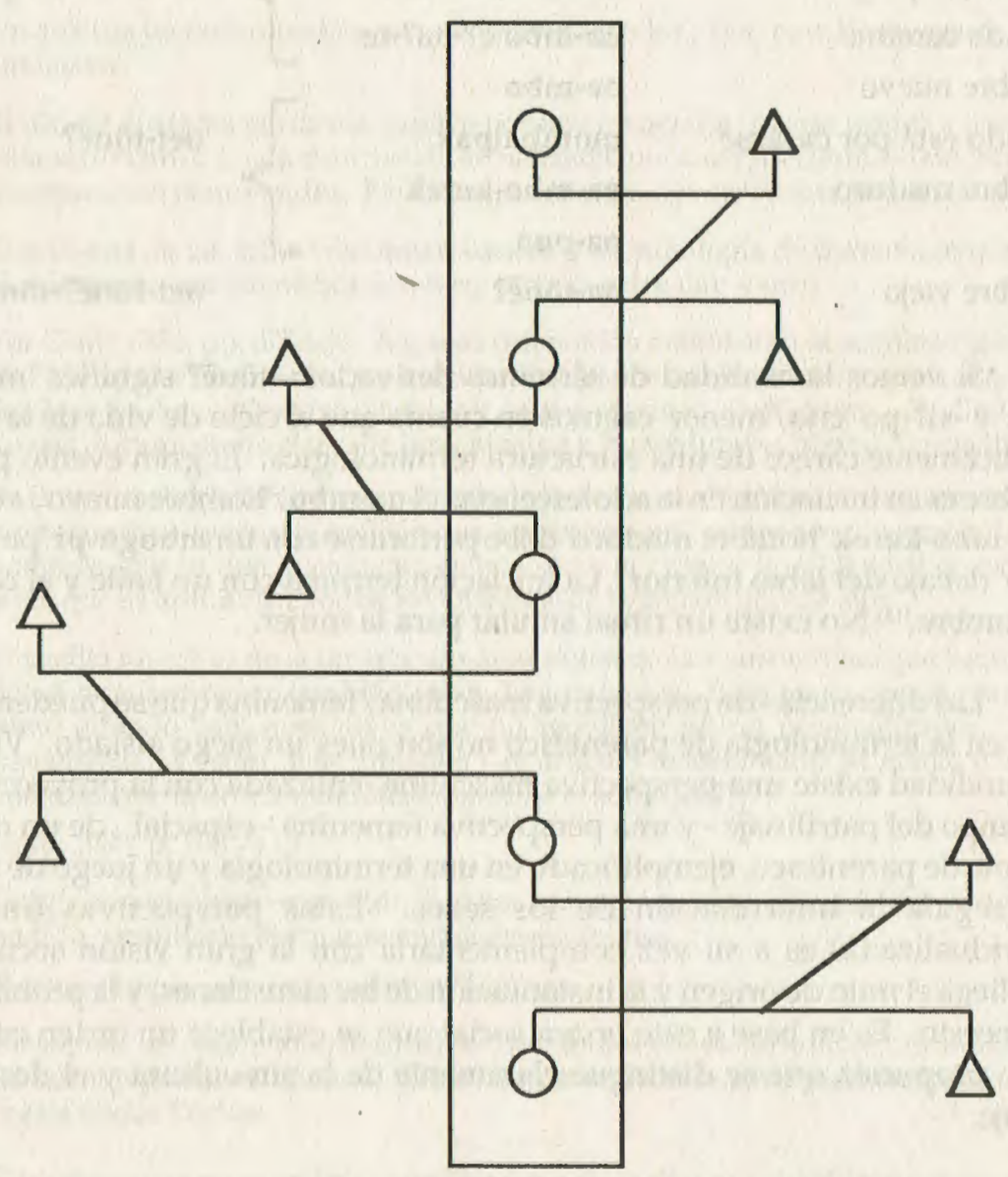




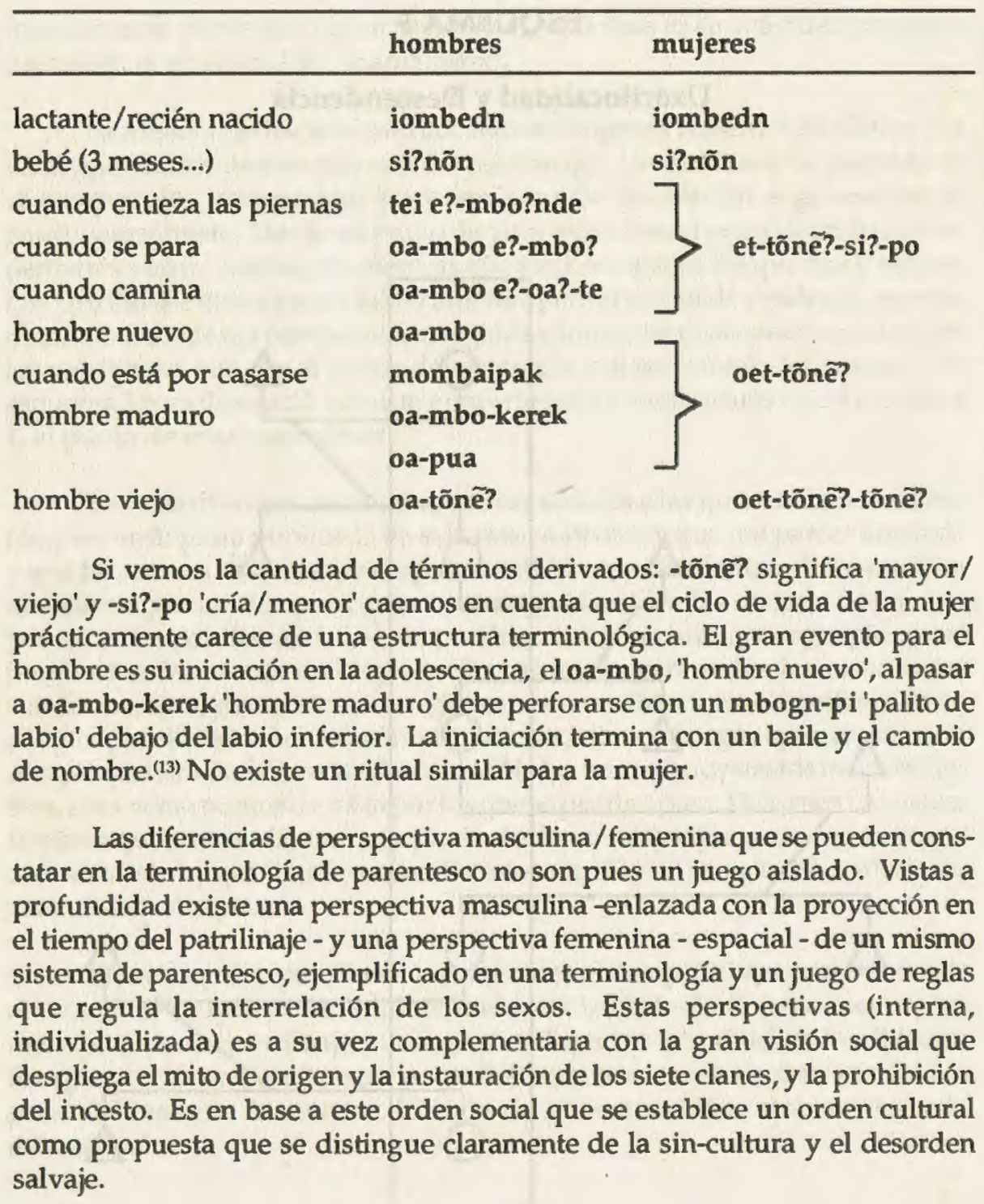




\section{NOTAS}

(1) Un Informante me dice que Sapiteri es sólo para los de fuera, en realidad se dice Kapiteri, del río Kapite.

(2) No supone, sin embargo, asumir una actividad inconsciente o una "estructura mental" subyacente, etc.

(3) Gray: 1983, p. $119-120$.

(4) Un análisis tentativo podría ser: oa- 'nominalizador', ? ẽn 'patrilinaje ajeno', -nda 'intensivo'.

(5) El uso de distintas grafias se explica por una ortografía inglesa (onju) y una castellana (onchiu). La pronunciación actualizada (por Gray) del término sugiere una fonemización como ondiu. No he tenido ocasión de corroborar esto en el campo.

(6) Esta es una de las asimetrias entre sistema y terminologfa de parentesco que nos previenen de una identificación muy estricta entre uno y otro.

(7) Ver Gray: 1983, pp.133-134. Algunas diferencias notables en la terminología son: En Shintuya se usan oa-ho y oa-ti-o para el 'padre clasificatorio', mientras que en San José oa-ho es el padre genético y oa-ti-o el padre clasificatorio. En Shintuya no estádocumentado el uso de huachiosipo y huachiumbu 'hijos del cuffado', etc.

En la terminología de Gray oa mã?mbui aparece como 'hermana de ego femenino'. No he constatado ese uso en Shintuya, tan sólo oa-má?mbuy como 'hermano' entre hombres, por lo que justamente se introduce el criterio igualdad/diferencia de sexo, que es aplicable a todos los términos de la generación de ego.

(8) El prefijo oa- no es en sí un artículo determinado. Los sustantivos que requieren de un nominalizador también están determinados. Pero no se puede usar oacomo artículo con sustantivos que no requieren de un nominalizador. Esos sustantivos ya están determinados ( el artículo determinado se marca 0 'cero', mientras que el artículo indeterminado es el sufijo -pi?).

(9) Gray: 1983, p. $108-113$

(10) Tengo conocimiento que Aldo Fuentes prepara un texto etnográfico; pero no he podido consultarlo porque se encuentra en prensa.

(11) Esta ceremonia ya no se realiza en Shintuya.

(12) Obsequiar un regalo matrimonial se dice: tindoi e?-iok, o también tindoia? e-nka 'hacer regalo matrimonial'. Si los miembros del otro patrilinaje son pocos se les regala varias flechas.

(13) Esta ceremonia no se realiza ya en Shintuya. Se realizaba vistiéndose con un ala de avede plumas mãtinõ y con coronas tangka. Perforarse el labio se dice e?-mbogntokoi, derivado de oa-mbogn 'labio' y e?-tokoi 'horadarse hueco/pinchar/perforar lentamente' distinto de e?-e-ka?'hacer hueco' y e?-ko 'clavar de golpe'. 


\section{BIBLIOGRAFIA}

FOX, ROBIN:

1971 Kinship and marriage. An anthropological perspective. Harmondsworth, Middlesex, England: Penguin Books Inc.

GRAY, ANDREW.

1983 The Amarakaeri: An ethnographic account of Harakmbut people Southeastern Peru. (tesis doctoral)

GRAY, ANDREW.

1984 Los Amarakaeri: una noción de estructura social. En: Amazonía Peruana, Vol. V, № 10, pp. 47-63

HELBERG CHÁVEZ, HEINRICH.

1984 Skizze einer Grammatik des Amarakaeri. Tesis doctoral (1982). Berlin.

HELBERG CHÁVEZ, HEINRICH.

1982 Die Verwandtschaftsterminologie des Amarakaeri. En: Festgabe für Antonio Tovar, Tübingen; Seminar für Vergleichende Sprachwissenschaft.

HELBERG CHÁVEZ, HEINRICH.

1989 Análisis funcional del verbo Amarakaeri. En: Temas de lingüística amerindia. Primer Congreso Nacional de Investigaciones LingüísticoFilológicas. Eds. Rodolfo Cerrón-Palomino, Gustavo Solís Fonseca, Lima: CONCYTEC-GTZ, pp.227-249.

MOORE, THOMAS R.

1979 SILanda "New-found tribe": The Amarakaeri Experience. En Dialectical Anthropology, Vol. 4, Ne 2, pp. 113-125

TORRALBA, ADOLFO.

1979 Los Harakmbut: nueva situación misionera. En: Antisuyo, № 3, pp. 83141. 